\title{
Dystocia, stillbirth, gestation length, and birth weight in Holstein, Jersey, and reciprocal crosses from a planned experiment
}

\author{
K. M. Olson, ${ }^{* 1}$ B. G. Cassell, ${ }^{*}$ A. J. McAllister, $†$ and S. P. Washburn $\ddagger$ \\ *Department of Dairy Science, Virginia Polytechnic Institute and State University, Blacksburg 24061 \\ †Department of Animal and Food Science, University of Kentucky, Lexington 40506 \\ ‡Department of Animal Science, North Carolina State University, Raleigh 27695
}

\section{ABSTRACT}

Holstein and Jersey cows were mated to 4 Holstein (H) bulls and 4 Jersey $(\mathrm{J})$ bulls to create HH, HJ, JH, and JJ genetic groups (sire breed listed first) in a diallele crossbreeding scheme. Calvings $(\mathrm{n}=756)$ occurred in research herds in Virginia, Kentucky, and North Carolina with 243, 166, 194, and 153 calvings in the HH, HJ, JH, and JJ groups, respectively. Birth weights (BW), dystocia scores (0 for unassisted and 1 for assisted), and stillbirth (0 for alive or 1 for dead within $48 \mathrm{~h}$ ) were recorded at calving. Gestation lengths (GL) were determined from breeding dates. An animal model was used to analyze BW and GL, and an animal model with logistic regression was used for dystocia and stillbirth. Fixed effects considered for model inclusion were genetic group, herd-year-season, sex, parity (primiparous or multiparous), twin status, and gestation length. Genetic group and effects significant in the model building process were kept in the final model for each trait. Heifer calves had lower BW, shorter GL, and had a lower odds ratio (0.53) for dystocia than bull calves. Twins had lower BW, shorter GL, were 3.86 times more likely to experience dystocia, and 7.80 times more likely to be stillborn than single births. Primiparous cows had calves with lower BW, shorter GL, were 2.50 times more likely to require assistance at birth, and were 2.35 times more likely to produce stillborns than calves from multiparous cows. Genetic group did not affect GL. Least squares means $(\mathrm{kg})$ for BW were $37.7 \pm 1.1,29.1 \pm 1.1$, $30.3 \pm 1.0$, and $22.5 \pm 1.3$ for HH, HJ, JH, and JJ, respectively. Animals in $\mathrm{HH}$ weighed more than animals of other genetic groups; the JJ group had the smallest BW, with no differences for BW between HJ and JH. Probability of dystocia in JJ and $\mathrm{JH}$ were $5.73 \%$ and $18.98 \%$ of $\mathrm{HH}$. Calves in HJ and $\mathrm{HH}$ were not different for dystocia. Calves in HJ were 3.38 times more likely to be stillborn than calves in $\mathrm{JH}$, but no other genetic

Received March 30, 2009.

Accepted September 11, 2009.

${ }^{1}$ Corresponding author: kmolson@vt.edu group differences were significant for probability of stillbirth. Groups HJ and JH differed for calving traits, with JH crosses experiencing less dystocia than HJ; JJ showed no indication of dystocia. No differences were observed between $\mathrm{HH}$ and JJ for stillbirths. Additional investigation of stillbirths in Jerseys is justified.

Key words: crossbreeding, dystocia, stillborn

\section{INTRODUCTION}

Calving is a stressful time in a cow's life and the amount of stress is affected by high birth weights, dystocia, and stillbirth. Calving difficulty can result in the loss of a calf and can lead to various health problems of cows. Dematawewa and Berger (1997) reported additional costs for births requiring assistance of $\$ 96.48$ to $\$ 397.61$ depending on assistance needed. Meyer et al. (2001) reported that $23 \%$ of primiparous Holstein cows required assistance at calving and $10 \%$ of births from primiparous Holstein cows resulted in a stillbirth. They documented an increase in stillbirths over a 10-yr period and implicated dystocia as a causative factor of stillbirths. They estimated that stillbirths cost the US dairy industry $\$ 125$ million a year.

National genetic evaluations for dystocia have been available in the United States since 1980 for Holsteins (Berger, 1994) and evaluations for stillbirths in Holsteins since 2006 (Cole et al., 2007). Genetic evaluations are also available for dystocia in Brown Swiss in the United States. Currently, genetic evaluations for calving traits in Jersey cattle are not available in the United States. Cole et al. (2005) reported an incidence of dystocia in the Jersey breed of 0.5 to $0.7 \%$, which was too low to justify a genetic evaluation. This study, however, did not examine stillbirths. Other countries have also reported very low incidence for dystocia in the Jersey breed, but have included estimation of breeding values for calving traits in their genetic evaluation systems (Pedersen et al., 2009).

Even with sophisticated genetic evaluations for calving problems, some producers in the United States have turned to crossbreeding to avoid calving problems, 
particularly with Holstein heifers. A survey by Weigel and Barlass (2003) revealed that producers mated their purebred Holsteins to another breed to help avoid calving problems. Calving difficulties could be affected by direct additive, direct heterosis (genes in the calf), maternal heterosis, maternal genetic effects (genes in the dam), and recombination. Several studies have shown benefits in calving difficulties in a crossbreeding system with various breeds (Touchberry, 1992; Heins et al., 2006; Maltecca et al., 2006). Many of these studies have examined the purebred Holstein as the dam, but the literature is sparse for births to Jersey and Holstein dams in the same study.

Touchberry (1992) noted that crossbred calves of Guernsey and Holstein parents experienced fewer stillbirths than the purebred Holstein births. Weigel et al. (2008), however, found crossbred cows $(75 \%$ Holstein $\times$ $25 \%$ Jersey) had higher dystocia scores (2.27 to 1.73 ) than purebred Holstein cows for first calving when bred to Holstein bulls. Heins et al. (2006) reported that a lower proportion of crossbred calves were stillborn compared with purebred Holstein calves. The improvement of the crossbred calves could have been from direct genetic effects, maternal genetic effects, or a combination of the effects, but could not be specifically determined because of the design of the experiment. Heins et al. (2006) also found that crossbred dams had less dystocia than purebred dams, and certain crossbred cows (Montbéliarde/Holstein and Scandinavian Red/Holstein) had fewer stillbirths than Holstein dams. Jersey-sired calves out of Holstein dams have less dystocia than pure Holsteins (Heins et al., 2003). A Danish study found unfavorable heterosis for direct effects (genetic effects related to the calf) in dystocia and stillbirths in heifers, and found a favorable heterosis for maternal effects (effects related to the dam) for both dystocia and stillbirths (Sorensen et al., 2008).

The objectives of this study were to examine differences in dystocia, stillbirth, gestation length, and birth weight for calves born into a designed breeding project involving Holsteins, Jerseys, and reciprocal crosses.

\section{MATERIALS AND METHODS}

\section{Experimental Design}

Data on crossbred performance can originate in commercial herds or from designed experiments. Field data are generally more numerous, which can produce accurate estimates of breed group comparisons, but will not necessarily be available on those breed crosses of interest to commercial producers. Data recording from commercial herds in the United States is voluntary, and will be only as complete as herd management and data recording systems permit. When interest in crossbreeding increased in the United States in the late 1990s, field data on crossbreds were sparse, often incomplete, and subject to systematic biases such as sire selection and animal management. Field data were not adequate for information requirements of dairy producers. In response, researchers from 3 universities, Virginia Tech, the University of Kentucky, and North Carolina State University, cooperated to conduct a planned crossbreeding experiment involving university research herds and the Holstein $(\mathbf{H})$ and Jersey $(\mathbf{J})$ breeds.

The Virginia Tech and Kentucky herds consisted of purebred Holstein and Jersey cows at the start of the project and have been managed under a conventional system utilizing stored forages. The Center for Environmental Farming Systems in Goldsboro, North Carolina, joined the project about a year after it was initiated in the other 2 herds. The North Carolina herd is pasture based, calves all cows in fall and winter, and it has utilized a Holstein-Jersey rotational crossbreeding system for several years. Virginia Tech included about 180 cows with a 2:1 ratio of Holsteins to Jerseys at the start of the project. Kentucky included about 140 cows, also with a 2:1 ratio of Holsteins to Jerseys. The North Carolina herd of about 180 cows included about 35 cows in each purebred group with the rest of the herd composed of crosses and backcrosses involving Holstein and Jersey breeds only. The crosses and backcrosses were not included as dams, even though they could have contributed information for maternal effects. The project used only purebred dams to produce the offspring used in the current study. The project called for about 40 animals each in $\mathrm{HH}, \mathrm{HJ}, \mathrm{JH}$, and JJ groups (breed of sire first) at Virginia Tech, about 20 animals per group at Kentucky, and about 15 per group at North Carolina.

Breeding programs followed at the 3 herds used AI and Holstein and Jersey bulls routinely available through the AI industry serving the United States. Table 1 indicates that 277 Holstein dams delivered calves in the project, including both sexes and stillbirths. These cows were sired by 101 different Holstein bulls and were themselves daughters of 231 different Holstein cows. Fewer Jersey dams, 188, contributed calves to the project, reflecting the smaller Jersey populations in the Virginia Tech and Kentucky herds. These cows were sired by 64 different bulls out of 155 different Jersey dams. Historic selection objectives varied by herd so that dams of project animals represented a broad sample of genetic material available to Holstein and Jersey breeders in the United States in recent years.

Project animals were sired by 8 different bulls, 4 from each breed, as shown in Table 2. These bulls were from one bull stud, and all were alive and producing semen 
Table 1. Number of ancestors in 3-generation pedigrees of calves born to the crossbreeding project and included in this analysis

\begin{tabular}{lccccc}
\hline Breed of dam & Dams & Sires of dams & $\begin{array}{c}\text { Sires of sires } \\
\text { of dams }\end{array}$ & Dams of dams & $\begin{array}{c}\text { Sires of dams } \\
\text { of dams }\end{array}$ \\
\hline Holstein & 277 & 101 & 44 & 231 & 120 \\
Jersey & 188 & 64 & 32 & 155 & 83 \\
\hline
\end{tabular}

at the time of selection. They were chosen to represent a diversity of lifetime economic merit as defined by Net Merit (VanRaden et al., 2006). Our objective was to select a bull from the 60th, 70th, 80th and 90th percentiles within each breed. Final choices were constrained considerably by availability of the bulls for research use. We also required a diversity of pedigrees to control inbreeding in purebred genetic lines. We used bulls producing semen to allow a companion research trial involving heterospermic semen conducted concurrently with the establishment of the crossbreeding project (Kasimanickam et al., 2006). The 8 bulls chosen reflect a range of Net Merit based on April 2002 genetic evaluations. Our effort to create pedigree diversity among foundation bulls was not entirely successful. Some male ancestors appeared up to 3 times in early generations. The problem was most acute for Jerseys.

Proofs on the foundation bulls changed during the project. Table 2 shows the most recent ranking of foundation bulls within their respective breeds for the current Net Merit index, which has changed since 2002. The highest ranking bull on current information, Cooper, was originally one of the 2 lowest ranking bulls. The lowest ranking Jersey, Freedom, ranked substantially lower in January 2009 than when he was first selected. Jerseys, in general, declined more than Holsteins during the years since selection. Choice of foundation sires was not affected by genetic evaluations for calving ease or stillbirth percentage. Such information is available for
Holstein but not for Jersey sires in the United States. The least favorable evaluations for percentage of difficult first births and stillbirths were for Dane, based on April 2009 evaluations. He was not an outlier for calving dystocia. The most favorable calving ease evaluations, for Breton and Cooper, would qualify them for use on heifers on many Holstein dairy farms.

We assigned bulls as mates for cows with the intent to produce almost equal progeny group size. Purebred matings were arranged to avoid inbreeding as much as possible. Relationships between mating pairs within the Jersey breed were more difficult to arrange than for Holsteins, as common male ancestors frequently appeared at the grandsire level.

\section{Data}

Calving dystocia, stillbirths, and birth weights were recorded as project animals were born at the 3 research dairies between June 2003 and March 2007. Dystocia was measured on a 1 to 5 scale with $1=$ no assistance, $2=$ slight problem but required no assistance, $3=$ required assistance, $4=$ considerable force, and $5=$ extreme difficulty. Observations in individual categories were sometimes limited, so dystocia scores of 1 or 2 were coded as unassisted, and scores of 3 to 5 were coded as assisted. Stillbirth was coded as 0 if the calf was born alive and survived past $48 \mathrm{~h}$ and 1 if they did not survive that long. Birth weights were recorded

Table 2. Basic pedigree and related information for foundation bulls used in the cooperative crossbreeding project

\begin{tabular}{|c|c|c|c|c|c|c|c|c|}
\hline \multirow[b]{2}{*}{ NAAB code $^{1}$} & \multirow[b]{2}{*}{$\begin{array}{l}\text { Name of } \\
\text { bull }\end{array}$} & \multirow[b]{2}{*}{ Sire of bull } & \multirow[b]{2}{*}{$\begin{array}{l}\text { Sire of sire } \\
\text { of bull }\end{array}$} & \multirow[b]{2}{*}{$\begin{array}{l}\text { Sire of dam } \\
\text { of bull }\end{array}$} & \multicolumn{2}{|c|}{ Rank for Net Merit } & \multirow[b]{2}{*}{$\begin{array}{l}\text { Difficult births } \\
\text { in heifers, }{ }^{3} \%\end{array}$} & \multirow[b]{2}{*}{ Stillbirths, ${ }^{3} \%$} \\
\hline & & & & & April $2002^{2}$ & January 2009 & & \\
\hline 7H5112 & Breton & Chesapeake & Mark & Winken & 40 & 39 & 7 & 8.1 \\
\hline $7 \mathrm{H} 5710$ & Dane & Zebo & Melwood & Mascot & 95 & 45 & 10 & 10.4 \\
\hline $9 \mathrm{H} 2315$ & Cooper & Emory & Blackstar & Winken & 53 & 73 & 7 & 8.0 \\
\hline $9 \mathrm{H} 2315$ & Jasper & Celsius & Bellman & Blackstar & 85 & 18 & 8 & 8.6 \\
\hline 7J424 & Freedom & Glenwood & Duncan & Sooner & 56 & 2 & $\mathrm{NA}^{4}$ & NA \\
\hline 7J442 & Paramont & Berretta & Sooner & Duncan & 99 & 56 & NA & $\mathrm{NA}$ \\
\hline 7J498 & Elevation & Barber & Duncan & Sky Line & 83 & 12 & NA & NA \\
\hline 7J472 & Parade & Alf & Q Royal & Berretta & 69 & 38 & NA & $\mathrm{NA}$ \\
\hline
\end{tabular}

${ }^{1}$ National Association of Animal Breeders animal number.

${ }^{2}$ Net Merit is an index of lifetime economic merit used in the United States. The traits included in Net Merit and weights applied to each have changed since selection of foundation sires in April 2002.

${ }^{3}$ Difficult births in heifers and stillbirth evaluations are from April 2009 genetic evaluations.

${ }^{4}$ Evaluations for difficult births and stillbirths are not available for Jerseys in the United States. 
Table 3. Distributions for dystocia, stillbirth, sex, and twin status and ranges and means for gestation length and birth weight, for 4 genetic groups $^{1}$

\begin{tabular}{|c|c|c|c|c|c|c|c|c|}
\hline Trait & \multicolumn{2}{|c|}{$\mathrm{HH}(\mathrm{n}=243)$} & \multicolumn{2}{|c|}{ HJ $(\mathrm{n}=166)$} & \multicolumn{2}{|c|}{$\mathrm{JH}(\mathrm{n}=194)$} & \multicolumn{2}{|c|}{$\mathrm{JJ}(\mathrm{n}=153)$} \\
\hline Unassisted & 55 & 137 & 38 & 102 & 46 & 137 & 47 & 103 \\
\hline \multicolumn{9}{|l|}{ Stillbirth } \\
\hline Dead & 18 & 8 & 7 & 11 & 1 & 9 & 5 & 6 \\
\hline Male & 43 & 88 & 28 & 58 & 23 & 80 & 23 & 59 \\
\hline Female & 43 & 68 & 19 & 61 & 24 & 67 & 24 & 47 \\
\hline \multicolumn{9}{|l|}{ Twin status } \\
\hline Single & 78 & 145 & 46 & 117 & 45 & 123 & 44 & 104 \\
\hline Twin & 8 & 12 & 1 & 2 & 2 & 24 & 3 & 2 \\
\hline \multicolumn{9}{|l|}{ Birth weight } \\
\hline Mean & 39.50 & 42.74 & 30.93 & 34.83 & 32.15 & 35.14 & 23.42 & 27.00 \\
\hline \multicolumn{9}{|l|}{ Gestation } \\
\hline Maximum & 291 & 299 & 289 & 293 & 288 & 290 & 302 & 302 \\
\hline
\end{tabular}

${ }^{1}$ Breed of sire listed first: $\mathrm{H}=$ Holstein; $\mathrm{J}=$ Jersey.

${ }^{2}$ Primiparous dams.

${ }^{3}$ Multiparous dams.

shortly after calving. Gestation length was relative to a breeding date producing a confirmed pregnancy by a veterinarian at Virginia Tech and North Carolina or confirmed by ultrasound in the Kentucky herd and followed by a subsequent calving.

Gestation lengths that were \pm 3 standard deviations (where 1 SD was $8 \mathrm{~d}$ ) from the mean of $279 \mathrm{~d}$ were excluded, removing 8 records. The final data set included 756 births with 243, 166, 194, and 153 births for $\mathrm{HH}$, HJ, JH, and JJ calves, respectively. Births by university were 419, 216, and 121 for Virginia Tech, Kentucky, and North Carolina, respectively. Counts, means, and ranges for the data are in Table 3.

Sires were not equally represented in all genetic groups (Table 4). Differences reflect differences between sires in success rates in a competitive fertilization study (Kasimanickam et al., 2006). That trial involved only the Virginia Tech and Kentucky herds. Holstein sires were successful in nearly $70 \%$ of all heterospermic matings. Later matings using homospermic inseminates balanced progeny group sizes within genetic groups to a considerable degree. However, older animals in the Virginia Tech and Kentucky herds are more frequently sired by Holstein than by Jersey bulls.

\section{Statistical Analyses}

Data were analyzed using an animal model in ASREML (Gilmour et al., 2006). The models included variables that were significant $(P<0.10)$, with the

Table 4. Number of offspring for sires and genetic groups ${ }^{1}$

\begin{tabular}{llrrrrr}
\hline NAAB $^{2}$ & Sire short name & HH & HJ & JH & JJ & Total \\
\hline 7H5112 & Breton & 36 & 26 & 0 & 0 & 62 \\
7H5710 & Dane & 77 & 50 & 0 & 0 & 127 \\
9H2344 & Cooper & 53 & 46 & 0 & 0 & 99 \\
9H2315 & Jasper & 77 & 44 & 0 & 0 & 121 \\
7J424 & Freedom & 0 & 0 & 48 & 37 & 85 \\
7J442 & Paramont & 0 & 0 & 54 & 39 & 93 \\
7J498 & Elevation & 0 & 0 & 44 & 40 & 84 \\
7J472 & Parade & 0 & 0 & 48 & 37 & 85 \\
Total & & 243 & 166 & 194 & 153 & 756 \\
\hline
\end{tabular}

${ }^{1}$ Breed of sire listed first: $\mathrm{H}=$ Holstein; $\mathrm{J}=$ Jersey.

${ }^{2}$ National Association of Animal Breeders animal number. 
exception of genetic group or the regression on components of genetic group differences, which were included in all models, regardless of significance levels. The model used for birth weight was

$$
y=\mathbf{X} \boldsymbol{\beta}+\mathbf{Z} \boldsymbol{\alpha}+e,
$$

where $y$ was the observation of birth weight; $\boldsymbol{\beta}$ was solution vector for fixed effects, which included genetic group (HH, HJ, JH, or JJ), herd-year-season (where season consisted of 4-mo intervals with 28 total groups), twin status (single or twin), parity of the dam (primiparous or multiparous), and sex of the calf (bull or heifer); $\boldsymbol{\alpha}$ was the solution vector for the random animal effects; $\mathbf{X}$ and $\mathbf{Z}$ were incidence matrices for fixed and random effects; and $e$ was the random residual. A Bonferroni adjustment was used for the confidence intervals of genetic groups to adjust for multiple comparisons.

Another analysis was used to determine the type of genetic control where genetic groups were replaced by linear regression on coefficients (Robison et al., 1981). The coefficients for the genetic groups were partitioned into percentage Holstein genes in the calf (direct genetic effects), percentage Holstein genes in the dam of the calves (maternal genetic effects), and percentage heterosis in the calf (direct heterosis). Table 5 shows the coefficients by genetic group. Maternal heterosis cannot be estimated from this design because no crossbred dams contributed to calving records. All other variables in model [1] were the same, regardless of whether genetic groups or coefficients for type of genetic control were used.

The model for gestation length was simplified by removal of herd-year-season effects, which were not significant $(P>0.10)$ in the model building process.

Dystocia scores were converted to "assisted" or "unassisted." Observations received a 1 if the dystocia score was $>2$ and a 0 otherwise. An animal model using logistic regression in ASREML (Gilmour et al., 2006) was used to account for the binary nature of the stillbirth and dystocia data. The model for dystocia was

$$
\eta=\mathbf{X} \boldsymbol{\beta}+\mathbf{Z} \boldsymbol{\alpha}+e
$$

where $\eta$ was the vector of the logits of the observed events; $\boldsymbol{\beta}$ was the solution vector of fixed effects and included herd, genetic group, twin status, parity of the dam, and sex of the calf; and $\boldsymbol{\alpha}$ includes the solutions from the random animal effects; $\mathbf{X}$ and $\mathbf{Z}$ were incidence matrices for the fixed and random effects; and $e$ was the random error term. Herd-year-season was not significant in the original model, but herd effects did account for significant variation and was included. In a separate analysis, genetic group was replaced by direct genetic effects, maternal genetic effects, and direct heterosis components as explained for model [1].

The model for mortality was less complex than that for dystocia. Herd, year, season, and sex were not significant $(P>0.10)$ in the model building process. The model for mortality included fixed effects of genetic group, twin status, parity, and random animal effects.

The relationships of explanatory variables with stillbirth and dystocia were investigated by use of odds ratios (OR), and significant OR were based on a $95 \%$ confidence interval. A Bonferroni adjustment was made to the confidence interval for genetic group comparisons to account for multiple comparisons (Ott and Longnecker, 2001). The occurrence of dystocia or stillbirth was modeled as 1 , so OR $>1$ indicate a higher probability that the event occurred, whereas OR $<1$ indicate lower probabilities of occurrence of the event. Johanson and Berger (2003) found that birth weight more effectively accounted for variation in stillbirth than did sex of the calf. Birth weight was initially included in the model for stillbirths. However, birth weight and genetic group are intricately related in these data. With the interest in genetic group comparisons in this study, we chose to exclude birth weight as an explanatory variable for dystocia and stillbirths. Gestation length was also originally included but was not significant for either trait.

\section{RESULTS AND DISCUSSION}

\section{Birth Weights and Gestation Length}

Analyses of gestation length and birth weight are in Table 6. Herd-year-season of calving was significant for birth weight $(P<0.01)$ but did not significantly affect gestation length. Sex of calf was significant $(P<0.05)$ for birth weight and gestation length in that bull calves weighed more and had a longer gestation length than heifer calves. Twinning explained significant variation for birth weight and gestation length $(P<0.05)$, with twins weighing less and having shorter gestation lengths. Calves from primiparous cows had lower birth weights and shorter gestation lengths than those from multiparous cows.

Genetic group explained significant variation in birth weight, but genetic group differences and genetic group

Table 5. Coefficients assigned to each genetic group ${ }^{1}$ for regression analysis to estimate purebred effects of Holstein genes, maternal effects of Holstein genes, and heterosis

\begin{tabular}{lclll}
\hline Component & HH & HJ & JH & JJ \\
\hline Direct genetic effects & 1 & 0.5 & 0.5 & 0 \\
Maternal genetic effects & 1 & 0 & 1 & 0 \\
Direct heterosis & 0 & 1 & 1 & 0 \\
\hline
\end{tabular}

${ }^{1}$ Breed of sire listed first: $\mathrm{H}=$ Holstein; $\mathrm{J}=$ Jersey. 
Table 6. Least squares means for gestation length and birth weight

\begin{tabular}{lcc}
\hline Item & Birth weight, kg & Gestation length, d \\
\hline Genetic group $^{1}$ & & \\
HH & $37.71^{\mathrm{a}} \pm 1.07$ & $277.3 \pm 1.2$ \\
HJ & $29.12^{\mathrm{b}} \pm 1.07$ & $277.2 \pm 1.2$ \\
JH & $30.30^{\mathrm{b}} \pm 1.01$ & $277.3 \pm 1.1$ \\
JJ & $22.51^{\mathrm{c}} \pm 1.27$ & $278.2 \pm 1.4$ \\
Lactation & & \\
Primiparous & $28.07^{\mathrm{a}} \pm 0.91$ & $277.0^{\mathrm{a}} \pm 0.93$ \\
Multiparous & $31.50^{\mathrm{b}} \pm 0.86$ & $278.0^{\mathrm{b}} \pm 0.98$ \\
Sex & & \\
Male & $31.08^{\mathrm{a}} \pm 0.88$ & $278.1^{\mathrm{a}} \pm 0.95$ \\
Female & $28.50^{\mathrm{b}} \pm 0.88$ & $277.0^{\mathrm{b}} \pm 0.95$ \\
Twin status & & \\
Twin & $26.17^{\mathrm{a}} \pm 1.04$ & $275.1^{\mathrm{a}} \pm 1.13$ \\
Single & $33.40^{\mathrm{b}} \pm 0.81$ & $279.9^{\mathrm{b}} \pm 0.90$ \\
Regression on genetic group coefficients ${ }^{2}$ & & \\
Direct genetic effects & $14.27 \pm 2.45$ & $\mathrm{NS}$ \\
Maternal genetic effects & $\mathrm{NS}$ & $\mathrm{NS}$ \\
Direct heterosis & $\mathrm{NS}$ & $\mathrm{NS}$ \\
\hline
\end{tabular}

${ }^{a-c}$ Estimates with different superscripts are significantly different, $P<0.05$.

${ }^{1}$ Sire breed by dam breed; $\mathrm{H}=$ Holstein; $\mathrm{J}=$ Jersey.

${ }^{2}$ Based from $0 \%$ Holstein genes moving to $100 \%$ Holstein genes.

components were not significant for gestation length. The HH genetic group had significantly higher birth weights than the $\mathrm{HJ}, \mathrm{JH}$, and JJ groups, whereas the JJ group had the lowest birth weight. The direct genetic effects were highly significant $(P<0.001)$, and calves with $100 \%$ Holstein genes were expected to weigh $14.3 \pm 2.4 \mathrm{~kg}$ more than calves with $100 \%$ Jersey genes. Reciprocal crosses HJ and JH did not differ for birth weight, and maternal genetic effects were not significant $(P=0.093)$. Direct heterosis for birth weight was $0.01 \%$ below the mid parent average and was not significant $(P=0.998)$. The difference between $\mathrm{HH}$ and the crossbred (HJ and $\mathrm{JH}$ ) calves is similar to the 7.9-kg difference between the Jersey $\times$ Holstein calves and purebred Holstein calves reported by Heins et al. (2003). Maltecca et al. (2006) reported that birth weights from $75 \%$ Holstein calves born to Holstein dams bred to crossbred Holstein-Jersey sires were lower by $1.9 \mathrm{~kg}$ compared with those of pure Holstein calves.

Effects of parity of the dam were consistent with literature estimates. Johanson and Berger (2003) reported that primiparous cows tended to have smaller calves than multiparous cows $(38.2 \mathrm{vs} .41 .7 \mathrm{~kg}$, a difference of $3.5 \mathrm{~kg}$ ). Our results were consistent with those findings with a 3.4-kg difference between the parities. Predicted means in this study were smaller at $28.07 \pm 0.91 \mathrm{~kg}$ for primiparous to $31.50 \pm 0.86 \mathrm{~kg}$ for multiparous dams. The combination of Jersey and Holstein sires and dams in our study would be expected to produce such results. Maltecca et al. (2006) reported a 3.2-kg difference between parity groups for Holstein dams. Maltecca et al. (2006) also reported differences between bull calves and heifer calves of $1.30 \pm 0.40 \mathrm{~kg}$. Our difference was slightly larger at $2.58 \mathrm{~kg}$.

Twinning rate in these data was $7.1 \%$ across the 3 herds, which was higher than $3.1 \%$ reported by Ghavi Hossein- Zadeh et al. (2008) and $4.4 \%$ by Kertz et al. (1997). Silva del Rio et al. (2007) reported that twinning rates ranged from 0.3 to $12 \%$ across farms. Johanson et al. (2001) reported PTA for twinning rate in Holstein bulls that ranged from 1.6 to $8 \%$ and actual twinning rates that ranged from 0.7 to $16.2 \%$ for sires. In the current study, the rate of twinning was higher from Holstein dams (10.5\%) than from Jersey dams $(2.5 \%)$ regardless of genetic group of calf $\left(\chi^{2}=17.8 ; P\right.$ $<0.001)$. Birth weight from twin births in Table 6 was $26.17 \pm 1.04 \mathrm{~kg}$, which was $22 \%$ less than single births. Kertz et al. (1997) found that twin births were $15 \%$ lighter than single births.

We found no significant differences between genetic groups for gestation length perhaps because only a small sampling of Holstein and Jersey sires was used. Silva et al. (1992) documented that Jerseys had shorter gestation lengths $(278 \mathrm{~d})$ than Holsteins $(280 \mathrm{~d})$. Gestation lengths for bull calves in our study were $0.99 \pm 0.37$ d longer than for heifer calves, which was consistent with the $1.1 \mathrm{~d}$ longer reported by Silva et al. (1992). Gestation lengths for twins were $4.82 \mathrm{~d} \pm 0.76$ less than single births.

Phenotypic variance and heritability estimates can be found in Table 7 . The heritability estimates obtained were $0.49 \pm 0.14$ for birth weight and $0.42 \pm 0.16$ for gestation length. These heritability estimates are from a small data set and apply to all genetic groups, which 
Table 7. Phenotypic variance and heritability for birth weight, gestation length, mortality, and dystocia

\begin{tabular}{lcc}
\hline Trait & Phenotypic variance & Heritability \\
\hline Birth weight & $20.78 \pm 1.53$ & $0.49 \pm 0.14$ \\
Gestation length & $29.38 \pm 2.20$ & $0.42 \pm 0.16$ \\
Mortality & $1.060 \pm 0.335$ & $0.06 \pm 0.30$ \\
Dystocia & $1.058 \pm 0.330$ & $0.06 \pm 0.30$ \\
\hline
\end{tabular}

were fit as fixed effects in the model. Some recent estimates of heritabilities for birth weight range from 0.46 to 0.53 (Groen and Vos, 1995; Coffey et al., 2006). Jamrozik et al. (2005) found the heritability for gestation length (analyzed as a trait of the calf) in Holsteins to be 0.22 , whereas VanRaden et al. (2004) reported an estimate of 0.10. Jamrozik et al. (2005) found that gestation length had an unfavorable genetic correlation with both stillbirth and dystocia, as longer gestation intervals produced more dystocia and more stillbirths. Our data set was too small to provide stable estimates of genetic correlations.

\section{Dystocia and Stillbirths}

Odds ratios and corresponding confidence intervals for dystocia and stillbirths are in Table 8. Significant effects for explaining variation in dystocia included twinning, parity of the dam, sex, herd, and genetic group. Significant effects for stillbirths included twinning, parity of the dam, and genetic group. Direct genetic effects and maternal genetic effects were significant for dystocia, but direct heterosis was not. Maternal genetic effects were significant for stillbirths, whereas direct genetic effects and direct heterosis effects did not have a significant impact on stillbirths.

Heifer calves were $53.5 \%$ as likely as bull calves to require assistance at birth. Bull calves accounted for $57 \%$ of stillbirths and for $54 \%$ of all calvings. Therefore, sex was not significant in the model building process for stillbirth data. Arithmetic means were $12 \%$ stillbirths for heifer calves and $15 \%$ stillbirths for bull calves from primiparous cows and $6 \%$ stillbirths for both bull and heifer calves from multiparous dams. Several recent studies have reported that bull calves have higher odds of (or more) stillbirths than heifer calves (Heins et al., 2006; Maltecca et al., 2006). However, Meyer et al. (2001) found that heifer calves had $12 \%$ higher odds for stillbirth than bull calves if they were from multiparous cows, but $7 \%$ lower odds if they were born from primiparous cows.

Parity of the dam was a significant source of variation for both dystocia and stillbirths. The calf from a primiparous cow was 2.50 times more likely to be born with assistance and 2.35 times more likely to have died than if they were born from a multiparous cow. Higher OR for dystocia in primiparous cows supports the findings of Johanson and Berger (2003), who reported 4.7 times higher probability for dystocia from primiparous compared with multiparous Holstein dams delivering Holstein calves. Our findings agree with those of Meyer et al. (2001) in which the expected probability of a stillbirth from a primiparous cow was $10 \%$ versus a multiparous estimate of $5 \%$ and with the OR of 2.43 for

Table 8. Odds ratios for dystocia and stillbirth and associated confidence intervals for the 4 genetic groups

\begin{tabular}{|c|c|c|c|c|c|c|}
\hline \multirow[b]{2}{*}{ Trait } & \multicolumn{3}{|c|}{ Dystocia } & \multicolumn{3}{|c|}{ Stillbirth } \\
\hline & $P$-value & Odds ratio & $\mathrm{CI}^{1}$ & $P$-value & Odds ratio & $\mathrm{CI}^{1}$ \\
\hline \multicolumn{7}{|l|}{ Genetic group $^{2}$} \\
\hline JJ vs. HH & $<0.0001$ & 0.0573 & $0.008-0.409$ & 0.5420 & 0.7765 & $0.262-2.230$ \\
\hline JH vs. HH & $<0.0001$ & 0.1898 & $0.066-0.549$ & 0.0343 & 0.4105 & $0.136-1.239$ \\
\hline HJ vs. HH & 0.4656 & 0.8069 & $0.373-1.745$ & 0.5420 & 1.3860 & $0.556-3.455$ \\
\hline JJ vs. HJ & 0.0005 & 0.0710 & $0.010-0.524$ & 0.1742 & 0.5601 & $0.183-1.712$ \\
\hline JJ vs. JH & 0.1366 & 0.3017 & $0.037-2.485$ & 0.1872 & 1.8920 & $0.720-4.967$ \\
\hline HJ vs. JH & 0.0009 & 4.255 & $1.396-11.67$ & 0.0068 & 3.3778 & $1.035-11.03$ \\
\hline \multicolumn{7}{|l|}{ Lactation } \\
\hline Primiparous vs. multiparous & 0.0004 & 2.4950 & $1.514-4.110$ & 0.0021 & 2.3505 & $1.378-4.090$ \\
\hline \multicolumn{7}{|l|}{ Sex } \\
\hline Female vs. male & 0.0162 & 0.5348 & $0.321-0.890$ & $\mathrm{NA}^{3}$ & NA & NA \\
\hline \multicolumn{7}{|l|}{ Twin status } \\
\hline Twin vs. single & 0.0007 & 3.8648 & $1.770-8.437$ & $<0.0001$ & 7.798 & $3.770-29.39$ \\
\hline \multicolumn{7}{|c|}{ Regression on genetic group comparison } \\
\hline Direct genetic effects & 0.0003 & 134.9 & $9.48-1,921$ & 0.1742 & 3.1456 & $0.600-16.48$ \\
\hline Maternal genetic effects & 0.0010 & 0.2295 & $0.098-0.539$ & 0.0069 & 0.2955 & $0.122-0.714$ \\
\hline Direct heterosis & 0.3274 & 2.095 & $0.489-8.989$ & 0.5757 & 0.7225 & $0.233-2.245$ \\
\hline
\end{tabular}

${ }^{1} 95 \%$ confidence interval (note breed CI is based on an $\alpha$ of 0.0085 to account for multiple comparisons).

${ }^{2}$ Breed of sire listed first: $\mathrm{H}=$ Holstein; $\mathrm{J}=$ Jersey.

${ }^{3}$ Was not included in the model because $P>0.1$ for the variable in the model building process. 
stillbirths from primiparous compared with multiparous dams reported by Johanson and Berger (2003).

Twin status affected OR for both dystocia and stillbirths. Twins were 3.86 times more likely to require assistance at calving and were 7.80 times more likely to be stillborn than single births. Silva del Rio et al. (2007) found that twins were 6.5 times more likely to be stillborn than single births.

Direct and maternal genetic effects explained significant variation for dystocia. Direct heterosis was not significant. The direct genetic effects were significant, because calves with $100 \%$ Holstein genes were 134.9 times more likely to require assistance at calving than calves with $100 \%$ Jersey genes. Maternal genetic effects were also significant: calves born to a Holstein dam were $22 \%$ as likely to require assistance at calving as those born to a Jersey dam. These results were consistent with the differences between genetic groups. The JJ group was only 5.7 and $7.1 \%$ as likely as the $\mathrm{HH}$ and HJ groups, respectively, to require assistance at birth. The JH group also had lower odds of having an assisted birth compared with the HH group, with an OR of 0.19 relative to $\mathrm{HH}$. The HJ and $\mathrm{HH}$ groups were not different for dystocia. The 2 crossbred groups differed from each other in that the HJ group was 4.26 times more likely to require assistance at birth than the JH group.

Our findings are consistent with recent literature on crossbreds in the United States. Heins et al. (2006) found that crossbred (breed of sire being Swedish Red and Brown Swiss) calves had lower dystocia than purebred Holstein calves. Maltecca et al. (2006) found that Holstein-sired calves were 1.24 times more likely than crossbred-sired calves (75\% Holstein) to require assistance at calving when used on Holstein dams. Our results contradict those of Sorensen et al. (2008) in which unfavorable direct heterosis for dystocia was significant for heifers. Our data were from current North American Holstein and Jersey genetics, whereas the results of Sorensen et al. (2008) were based on calvings from the 1970s to 1980s on Finnish Ayrshire, Danish Red, and Holstein-Friesian. Thus, breed or strain within breed differences could account for differences in effects of direct heterosis.

The only significant difference between the genetic groups for stillbirth was that HJ were 3.61 times more likely to be stillborn than JH calves. Crossbred calves born from a Holstein dam were less likely to be stillborn than crossbred calves born from a Jersey dam. Other genetic group differences were not significant, and neither direct genetic effects nor direct heterosis effects were significant. Notably, stillbirths did not differ between $\mathrm{HH}$ and JJ genetic groups. $P$-values were below 0.05 for some genetic group pairs. However, when multiple comparison adjustments were made, the $P$ - value would need to be 0.0085 to declare significance. Maltecca et al. (2006) found that calves from Holstein sires (vs. crossbred sires) were 1.42 times more likely to be stillborn. Heins et al. (2006) also reported reduced stillbirths from using Swedish Red sires compared with Holstein sires (15.1 to $7.7 \%$ ) on a Holstein dam.

Incidence of dystocia for the JJ genetic group was consistent with the literature. Cole et al. (2005) found that $92 \%$ of Jersey births had a dystocia score of 1 and found very small genetic differences between sires within the Jersey breed. Our data showed that less than $2.0 \%$ of purebred Jersey calves required assistance at calving. Although the JJ group did not have much calving difficulty, they were not immune to stillbirth problems. The JJ group was not different from the $\mathrm{HH}$ group for incidence of stillbirths. This is consistent with Pedersen et al. (2009) who reported incidence of stillbirths of 7.7 and $7.6 \%$ for Jersey bull and heifer calves from primiparous dams. More complete recording of stillbirth data for Jerseys in the United States is justified. Genetic evaluations for stillbirths in Jerseys may be useful.

The HJ and JH groups were different from each other for both dystocia and stillbirth. Maternal genetic effects were also significant for Holstein-Jersey crossbred calves. For calving purposes, it is advantageous to use a Jersey sire on a Holstein dam rather than the reciprocal mating. However, use of Holstein sires on Jersey dams resulted in similar dystocia and stillbirth odds as those in pure Holsteins.

Phenotypic variance and heritability estimates can be found in Table 7 . The estimates for heritability of stillbirth and dystocia were $0.06 \pm 0.29$ and $0.06 \pm$ 0.30 , respectively. Direct genetic variance for these traits is small, even with different genetic groups. Large standard errors reflect data limitations.

\section{CONCLUSIONS}

Twin births and births from primiparous cows produced higher odds of dystocia and stillbirths than single births or births to multiparous dams in these multibreed data from research herds and a designed breeding project. The higher twinning rate among Holstein dams compared with Jersey dams was an unexpected finding. Bull calves required more assistance at calving than heifer calves. Genetic groups differed for birth weight, dystocia, and stillbirths, but not for gestation length. Direct heterosis did not significantly affect birth weights, gestation length, dystocia, or stillbirths. The HH group had higher birth weights, but similar probabilities of dystocia and stillbirths as HJ. The HJ group was similar to the JH group in birth weight but both $\mathrm{HH}$ and $\mathrm{HJ}$ had higher odds of stillbirth and dystocia 
than the JH group. The significant differences between reciprocal crosses for dystocia indicates that Holstein dams had an advantage in maternal genetic effects over Jersey dams, but the added difficulty of Holstein genes for dystocia were much larger than the favorable maternal genetic effects. Thus, HH and JJ groups were significantly different for dystocia as expected, but use of Holstein sires with Jersey dams results in no greater dystocia or stillbirths compared with matings involving pure Holsteins. More aggressive data collection of stillbirths and possible addition of genetic evaluations for Jerseys are recommended.

\section{ACKNOWLEDGMENTS}

The authors thank Sharon Franklin, Jasmine Ware, and Christina Williams for assisting in data preparation and collection. We acknowledge the staff at research stations at Virginia Tech (Blacksburg), the University of Kentucky (Lexington), and at the Center for Environmental Farming Systems in North Carolina (Goldsboro) for their diligence in data recording. The authors are grateful for the financial support provided by Holstein USA (Brattleboro, VT), the American Jersey Cattle Club Research Foundation (Reynoldsburg, $\mathrm{OH}$ ), Animal Improvement Programs Laboratory (USDA, Beltsville, MD), and for the semen donations by Select Sires (Plain City, OH).

\section{REFERENCES}

Berger, P. J. 1994. Genetic prediction for calving ease in the United States: Data, models, and use by the dairy industry. J. Dairy Sci. 77:1146-1153.

Coffey, M. P., J. Hickey, and S. Brotherstone. 2006. Genetic aspects of growth of Holstein-Fiesian dairy cows from birth to maturity. J. Dairy Sci. 89:322-329.

Cole, J. B., R. C. Goodling Jr., G. R. Wiggans, and P. M. VanRaden. 2005. Genetic evaluations of calving ease for Brown Swiss and Jersey bulls from purebred and crossbred calvings. J. Dairy Sci. 88:1529-1539.

Cole, J. B., G. R. Wiggans, and P. M. VanRaden. 2007. Genetic evaluation of stillbirth in United States Holsteins using a sirematernal grandsire threshold model. J. Dairy Sci. 90:2480-2488.

Dematawewa, C. M. B., and P. J. Berger. 1997. Effect of dystocia on yield, fertility, and cow losses and an economic evaluation of dystocia scores for Holsteins. J. Dairy Sci. 80:754-761.

Ghavi Hossein-Zadeh, N., A. Nejati-Javaremi, S. R. Miraei-Ashtiani, and H. Kohram. 2008. An observational analysis of twin births, calf stillbirth, calf sex ratio, and abortion in Iranian Holsteins. J. Dairy Sci. 91:4198-4205.

Gilmour, A. R., B. J. Gogel, B. R. Cullis, and R. Thompson. 2006. ASReml User Guide Release 2.0 VSN International Ltd., Hemel Hempstead, UK.

Groen, A. F., and H. Vos. 1995. Genetic parameters for body weight and growth in Dutch Black and White replacement stock. Livest. Prod. Sci. 41:201-206.

Heins, B. J., L. B. Hansen, and A. J. Seykora. 2006. Calving difficulty and stillbirths of pure Holsteins versus crossbreds of Holstein with Normande, Montbeliarde, and Scandinavian Red. J. Dairy Sci. 89:2805-2810.
Heins, B. J., A. J. Seykora, L. B. Hansen, J. G. Linn, and W. P. Hansen. 2003. Effect of mating Holstein females to Holstein versus Jersey AI sires on fertility, dystocia, calf weight, and retained placenta. J. Dairy Sci. 86(Suppl. 1):130. (Abstr.)

Jamrozik, J., J. Fatehi, G. J. Kistemaker, and L. R. Schaeffer. 2005. Estimates of genetic parameters for Canadian Holstein female reproduction traits. J. Dairy Sci. 88:2199-2208.

Johanson, J. M., and P. J. Berger. 2003. Birth weight as a predictor of calving ease and perinatal mortality in Holstein cattle. J. Dairy Sci. 86:3745-3755.

Johanson, J. M., P. J. Berger, B. W. Kirkpatrick, and M. R. Dentine. 2001. Twinning rates in North American Holstein sires. J. Dairy Sci. 84:2081-2088.

Kasimanickam, R., R. L. Nebel, I. D. Peeler, W. L. Silvia, K. T. Wolf, A. J. McAllister, and B. G. Cassell. 2006. Breed differences in competitive indices of Holstein and Jersey bulls and their association with sperm DNA fragmentation index and plasma membrane integrity. Theriogenology 66:1307-1315.

Kertz, A. F., L. F. Reutzel, B. A. Barton, and R. L. Ely. 1997. Body weight, body condition score, and wither height of prepartum Holstein cows and birth weight and sex of calves by parity: A database and summary. J. Dairy Sci. 80:525-529.

Maltecca, C., H. Khatib, V. R. Schutzkus, P. C. Hoffman, and K. A. Weigel. 2006. Changes in conception rate, calving performance, and calf health and survival from the use of crossbred Jersey $\mathrm{x}$ Holstein sires as mates for Holstein dams. J. Dairy Sci. 89:27472754.

Meyer, C. L., P. J. Berger, K. J. Koehler, J. R. Thompson, and C. G. Sattler. 2001. Phenotypic trends in incidence of stillbirth for Holsteins in the United States. J. Dairy Sci. 84:1246-1254.

Ott, R. L., and M. Longnecker. 2001. An Introduction to Statistical Methods and Data Analysis. 5th ed. Wadsworth Publishing Company, Belmont, CA.

Pedersen, J., M. K. Sorensen, M. Toivonen, J. Eriksson, and G. P. Aamand. 2009. Report on Economic basis for a Nordic total merit index. Online. The Nordic Cattle Evaluation. http:// www.nordicebv.info/Publications/English/publicatuions+ny.htm Accessed May 18, 2009.

Robison, O. W., B. T. McDaniel, and E. J. Rincon. 1981. Estimation of direct and maternal additive and heterotic effects from crossbreeding effect in animals. J. Anim. Sci. 52:42-50.

Silva, H. W., C. J. Wilcox, W. W. Thatcher, R. B. Becker, and D. Morse. 1992. Factors affecting days open, gestation length, and calving interval in Florida dairy cattle. J. Dairy Sci. 75:288-293.

Silva del Rio, N., S. Stewart, P. Rapnicki, Y. M. Chang, and P. M. Fricke. 2007. An observational analysis of twin births, calf sex ratio, and calf mortality in Holstein dairy cattle. J. Dairy Sci. 90:1255-1264

Sorensen, M. K., E. Norberg, J. Pedersen, and L. G. Christensen. 2008. Invited review: Crossbreeding in dairy cattle: A Danish perspective. J. Dairy Sci. 91:4116-4128.

Touchberry, R. W. 1992. Crossbreeding effects in dairy cattle: The Illinois experiment, 1949 to 1969. J. Dairy Sci. 75:640-667.

VanRaden, P. M., A. H. Sanders, M. E. Tooker, R. H. Miller, H. D. Norman, M. T. Kuhn, and G. R. Wiggans. 2004. Development of a national genetic evaluation for cow fertility. J. Dairy Sci. 87:2285-2292.

VanRaden, P. M., and Multi-State Project S-1008. 2006. Net merit as a measure of lifetime profit: 2006 revision. Animal Improvement Programs Laboratory. http://aipl.arsusda.gov/reference/nmcalc. htm, Accessed May 22, 2009.

Weigel, K. A., and K. A. Barlass. 2003. Results of a producer survey regarding crossbreeding on US dairy farms. J. Dairy Sci. 86:41484154 .

Weigel, K. A., P. C. Hoffman, C. Maltecca, and T. J. Halbach. 2008. Production, conformation, health and fertility of backcross Holstein $\times$ Jersey cattle and their Holstein contemporaries. J. Dairy Sci. 91(Suppl. 1):766. (Abstr.) 